\title{
Alpha adrenergic receptors in renal pelvis and calyces: can rat models be used?
}

\author{
Osman Raif Karabacak', Nevzat Can Sener², Demet Yilmazer ${ }^{3}$, Yurdum Karabacak ${ }^{4}$, Hasan Nedim Goksel \\ Goktug ${ }^{1}$, Orhan Yigitbasi ${ }^{1}$, Murat Alper ${ }^{3}$ \\ ${ }^{1}$ Ministry of Health, Ankara Diskapi Yildirim Beyazit Teaching and Research Hospital, Department of \\ Urology; ${ }^{2}$ Ministry of Health, Adana Numune Teaching and Research Hospital, Department of Urology; \\ ${ }^{3}$ Ministry of Health, Ankara Diskapi Yildirim Beyazit Teaching and Research Hospital, Department of \\ Pathology; ${ }^{4}$ Department of Women's Health, Ministry of Health, Ankara, Turkey
}

\section{ABSTRACT}

We aimed, in this study, to determine the distribution of $\boldsymbol{\alpha}-1$ AR subtypes in rat and human pelvis and calyces, and to evaluate, by comparing these two species, the possibility of rats to be used as models for humans. Twenty patients with renal carcinoma were included into the study. The patients underwent radical nephrectomy for renal cell carcinoma (RCC). After nephrectomy, specimens were evaluated and excisional biopsies from healthy pelvis and calyces tissues were performed. When pathology confirmed the non-invasion of RCC, specimen was included into the study. A total of 7 adult Wistar Albino (250-300 g) female rats were used in this study. Specimens included renal pelvis and calyces. All specimens were evaluated under light microscope histopathologically. The concentrations of the receptor densities did not differ between the two groups. With the demonstration of the $\boldsymbol{\alpha}$ receptors in rat kidneys and calyces, many receptor-based studies concerning both humans and rats can take place. Novel medication targeting these subtypes -in this matter $\alpha 1 A$ and $\alpha 1 D$ for renal pelvis and calycesmay be helpful for expulsive therapy and/or pain relief. With the demonstration of similar receptor densities between human and rat tissues, rat model may be useful for $\boldsymbol{\alpha}$-receptor trials for renal pelvis and calyces.

\section{ARTICLE INFO}

\section{Key words:}

Rat model, Alpha Adrenergic

Receptors, Kidney, Pelvis, Calyx

Int Braz J Urol. 2014; 40: 683-9

Submitted for publication:

January 07, 2014

Accepted after revision:

April 06, 2014

\section{INTRODUCTION}

Alpha $1(\alpha-1)$ adrenoreceptors (AR) belong to the G-protein coupled receptor family (1). Gene cloning studies initially identified three subtypes of $\alpha-1 \mathrm{AR}: \alpha-1 \mathrm{~A}, \alpha-1 \mathrm{~B}$, and $\alpha-1 \mathrm{D}$ (2-7). The distribution of these receptors differs in the urinary system. Even though researchers focused on alpha receptors in bladder, ureter and prostate, fewer researchers focused on their distribution (8). Identification of the alpha adrenoreceptor subtypes in the urinary system, and their physiologic effects such as the contractions they cause in the ureter, bladder and urethra provided for the development of effective urological treatment methods (9). To these treatment methods, which have been confidingly used in benign prostatic hyperplasia (BPH) for many years, was added the urolithiasis cases in the last decade $(10,11)$. However, human and animal studies related to the receptor distribution in kidney have been insufficient. Although there are human and animal studies for modeling related 
to the bladder, ureter, and prostate, we have not been able to access any published studies relating to the renal pelvis and calyces $(1,4,5)$. We therefore aimed, through this study, to determine the distribution of $\alpha-1$ AR subtypes in rat and human pelvis and calyces, and to evaluate, by comparing these two species, the possibility of rats to be used as models for humans.

\section{MATERIAL AND METHODS}

Twenty patients with renal carcinoma were included into the study. The patients underwent radical nephrectomy for renal cell carcinoma (RCC). After nephrectomy, specimens were evaluated and excisional biopsies from healthy pelvis and calyces tissues were performed. When the pathologist confirmed non-invasion of RCC, specimen was included into the study.

A total of 7 adult Wistar Albino (250-300 g) female rats were used in this study. The animals were kept in a room at a constant temperature of $22 \pm 1^{\circ} \mathrm{C}$ and fed with standard pellet chow, and the room was maintained on a 12-hour light/dark cycle. Food and water were available ad libitum. All experiments were performed in conformity with the European Community Council Directive. This experimental study was carried out in the animal research laboratory of a teaching and research hospital and was approved by hospital's Animal Ethics Committee.

The animals were anesthetized intraperitoneally with combinations of ketamine $(60 \mathrm{mg} /$ $\mathrm{kg})$ and xylazine $(10 \mathrm{mg} / \mathrm{kg})$. All rats underwent bilateral nephrectomy after skin incision and tissue dissection.

The rats were sacrificed by overdose anesthesia. All specimens were kept in 10\% neutral formaldehyde solution.

Tissue specimens were prepared after routine procedures and then embedded in paraffin. Sections $(5 \mu \mathrm{m})$ were prepared from all specimens and stained with immunohistochemistry. During immunohistochemistry staining, ADRA 1A (Imgenex, IMG-71129), ADRA1B (Imgenex, IMG71127), ADRA 1D (Imgenex, IMG71130) antibodies (in $1 / 100$ dilution) were dripped to slides and $\alpha-1 \mathrm{~A}$, $\alpha-1 B$, and $\alpha-1 \mathrm{D}$ receptor subtypes were demons- trated by this method. With this method, cytoplasmic staining shows receptor concentration.

Specimens included renal pelvis and calyces. All specimens were evaluated by the same radiologist (DY), under light microscope histopathologically and photographs were taken (x40, $\mathrm{x} 100, \mathrm{x} 200$ ) by a pathologist (MA) blinded to the study groups. Slides were graded according to immune reactivities (Grade 0: No staining, Grade 1: positive staining less than 25\%, Grade 2: positive staining between 26-50\%, Grade 3: staining more than 50\%) (12).

\section{Statistical analysis}

Statistical analyses were performed using the Statistical Package for Social Sciences version 20.0 for MAC (SPSS Inc, Chicago, Illinois, USA). To test the analysis of data distribution, Kolmogorov-Smirnov test, and to test for equality of variances, Levene's test for equality of variances were used. One-way ANOVA was used for in-group comparisons and Tukey's test was used for group comparison. A value of $\mathrm{p}<0.05$ was considered statistically significant.

\section{RESULTS}

Twenty kidneys were harbored from twenty human patients and fourteen kidneys were harvested from 7 rats.

For human subjects, $\alpha-1 \mathrm{~A}$ and $\alpha-1 \mathrm{D}$ were found to be expressed more in both pelvis and calyces than $\alpha-1 B(p<0.05)$. Subtype distribution of $\alpha$ receptors in renal pelvis was $\alpha-1 \mathrm{D}(2.9)>\alpha-1 \mathrm{~A}$ (2.65) $>\alpha-1 B$ (1.35). In calyces, the distribution was $\alpha-1 \mathrm{D}(2.75)>\alpha-1 \mathrm{~A}(2.4)>\alpha-1 \mathrm{~B}(1.5)$.

Alpha-receptors have been demonstrated in rat renal pelvis and calyces. Even though all receptors have been demonstrated in rat kidney, subtypes differed. When stainings were analyzed, $\alpha-1 \mathrm{~A}$ and $\alpha-1 \mathrm{D}$ were found to be expressed more in both pelvis and calyces than $\alpha-1 \mathrm{~B}(\mathrm{p}=0.027$ and 0.013 for pelvis, and $\mathrm{p}=0.004$ and 0.006 for calyces, respectively). Subtype distribution of $\alpha$ receptors in renal pelvis was $\alpha-1 \mathrm{D}(2.42)>\alpha-1 \mathrm{~A}$ (2.35) $>\alpha-1 \mathrm{~B}(1.71)$. In calyces, it was $-1 \mathrm{D}(2.14)=\alpha-$ $1 \mathrm{~A}(2.14)>\alpha-1 \mathrm{~B}(1.35)$. 
$\alpha-1 \mathrm{~A}$ and $\alpha-1 \mathrm{D}$ receptors in renal pelvis and calyces were similar in both groups. There was a weak staining for $\alpha-1 \mathrm{~B}$ receptor subtypes. For renal pelvis, $\alpha-1 \mathrm{~A}$ staining was $2.35 \pm 0.49$, $\alpha-1 \mathrm{~B}$ was $1.71 \pm 0.82$ and $\alpha-1 \mathrm{D}$ was $2.42 \pm 0.51$. When staining of calyces was examined, $\alpha-1 \mathrm{~A}$ was $2.14 \pm 0.66, \alpha-1 \mathrm{~B}$ was $1.35 \pm 0.72$ and $\alpha-1 \mathrm{D}$ was $2.14 \pm 0.36$ for rat model (Figure-1).

The concentrations of the receptor densities did not differ between the two groups (Figure-2).

\section{DISCUSSION}

The full understanding of the adrenergic physiology of the urinary system is dependent on precise knowledge of the localization of the $\alpha-1$ ARs in tissue. Alpha-1 receptors are present in different densities in different regions of the urogenital system, and have significant functions. Identification of these receptors provided significant contribution to the treatment of urinary tract diseases. Three subtypes of $\alpha$ receptors $(\alpha-1 \mathrm{~A}, \alpha-1 \mathrm{~B}$, and $\alpha-1 D$ ) have been identified in the organs of different mammals by pharmacokinetics techniques (13). Rats were the most frequently used as experimental animals.

The presence of $\alpha-1$ receptors in the urinary system, and their distribution and densities in various organs were demonstrated through animal experiments in 1970s and 1980s ${ }^{(14-16)}$. The distribution of the alpha receptors in human ureter differs according to the ureteral level. Keun Park et al. reported that the expression of $\alpha-1 \mathrm{D}$ was significantly higher than $\alpha-1 \mathrm{~A}$ and $\alpha-1 \mathrm{~B}$ in the middle and upper ureter in humans whereas in distal ureter $\alpha-1 \mathrm{D}$ expression was higher than $\alpha-1 \mathrm{~A}$ and $\alpha-1 \mathrm{~B}$ but this difference was not significant statistically (6). Itoh et al. found that the expression of $\alpha-1 \mathrm{D}$ was greater in all regions of the ureter but it was $\alpha-1 \mathrm{D} \geq \alpha-1 \mathrm{~A}>\alpha-1 \mathrm{~B}$ in the proximal and medial ureter, similar to that of the total ureter. On the other hand, in distal ureter, $\alpha-1 \mathrm{D}$ expression was significantly higher than -1 A expression ${ }^{(17)}$. The expression of $\alpha-1$ receptor subtypes for renal pelvis and calyces were $\alpha-1 D>\alpha-1 \mathrm{~A}>\alpha-1 \mathrm{~B}$ in our human group. Walden, in a study conducted with humans, monkeys and rats in 1997, examined the $\alpha-1$ receptor subtypes in different regions of the bladder, and found that receptor subtype distribution was different in different regions of the tissue (18). Our study examined the expressions of alpha receptors in renal pelvis and lower calyces, and found their distribution as $\alpha-1 D>\alpha-1 A>\alpha-1 B$. No difference was observed in the receptor expressions in the pelvis and calyces. This result differs from the receptor distributions in the bladder and ureter.

Figure 1 - Pathologic images of rat and human pelvis and calyces. The brownish staining demonstrates alpha receptor stainings.
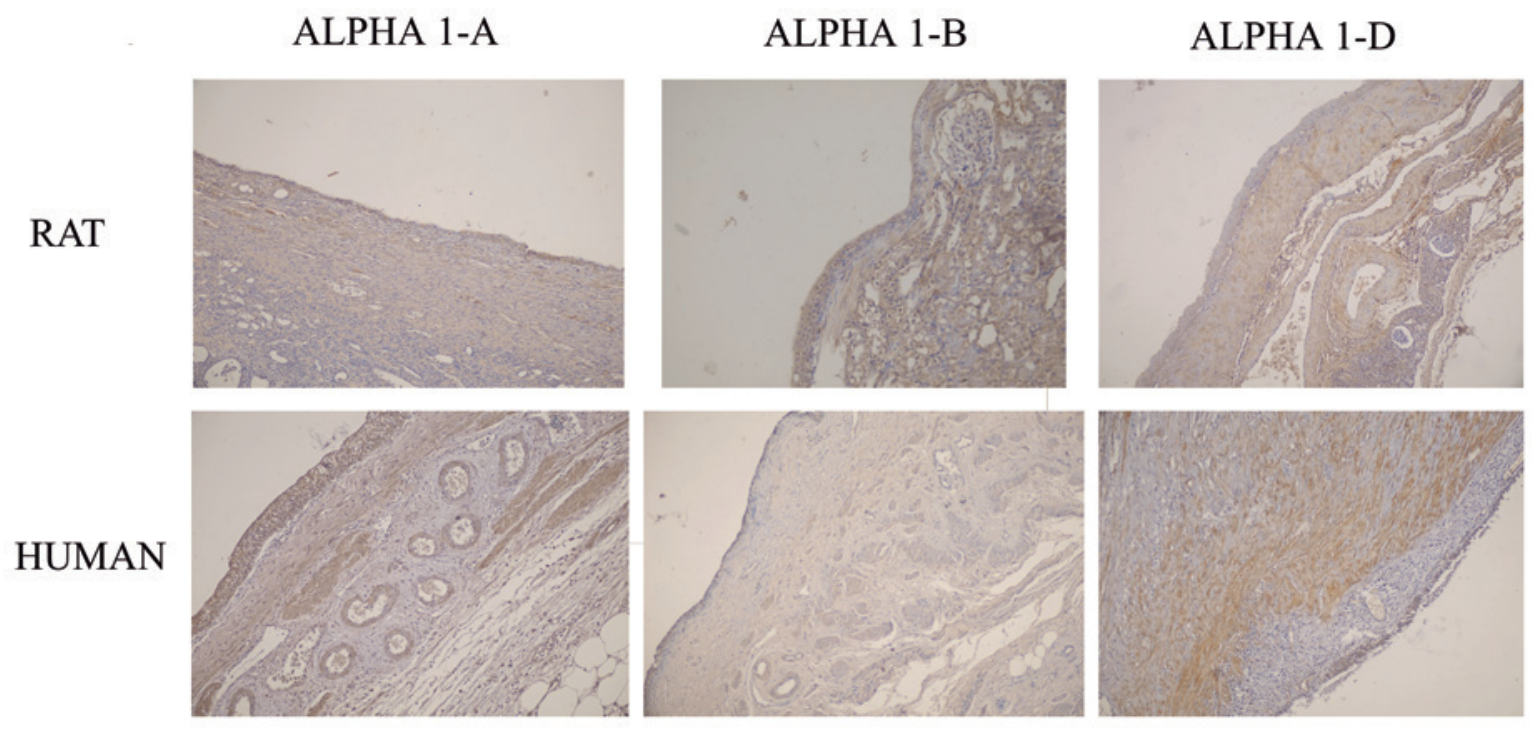
Figure 2 - Receptor distribution of human renal pelvis and calyces. Upper chart indicates renal pelvis, and the chart below, calyces.
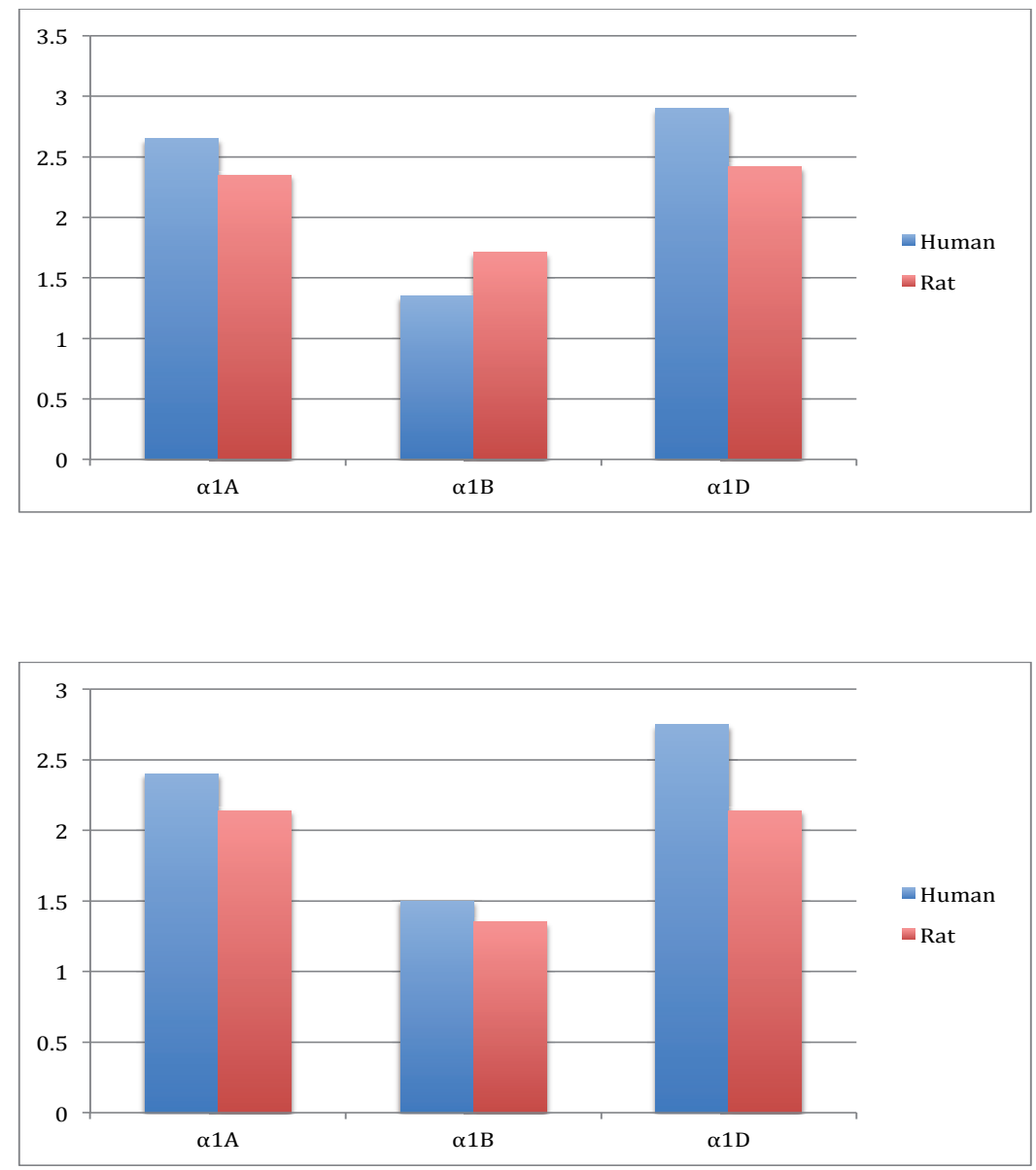

Hampel et al compared mice with the spinal cord and partial obstructive pattern and the control group, and found the distribution of alpha receptor subtypes as $\alpha-1 \mathrm{~A}>\alpha-1 \mathrm{D}>\alpha-1 \mathrm{~B}$ in the control group whereas it was $-1 \mathrm{D}>-1 \mathrm{~A}>-1 \mathrm{~B}$ in the group with obstructive rat bladder (19). Similarly, Lee et al. examined the bladder $\alpha$ receptor expression in rats with spinal cord injury, and demonstrated the expression as $\alpha-1 A>\alpha-1 D>\alpha-1 B$ in the control group, and $\alpha-1 D>\alpha-1 A>\alpha-1 B$ in rats with spinal cord injury (20). In our study with rats, the expression of $\alpha$ receptor subtypes was $\alpha-1 \mathrm{D}>\alpha-1 \mathrm{~A}>\alpha-1 \mathrm{~B}$ in the renal pelvis, as found in the control group rats in the study by Lee et al. and Hampbell et al., and in lower calyces it was $\alpha-1 \mathrm{D}(2.14)=\alpha-1 \mathrm{~A}(2.14)>\alpha-1 \mathrm{~B}(1.35)$.
Studies conducted to examine the similarities between different species by comparing human and animal tissues aimed to determine whether animals would be good models for humans. Pig, monkey, hamster, rabbit, and mouse have been used in alpha receptor studies. Especially in the urinary bladder studies, human and rats are different than the other species. Humans and rats show similarities with the $\alpha$ receptor subtype expressions of $\alpha-1 A>\alpha-1 D>\alpha-1 B$, and thus rats have been used more frequently in the studies aiming to form a model (21-23).

Walden et al. demonstrated, in their study where they examined the $\alpha-1 \mathrm{~A}$ receptor expressions in different regions of the monkey, rat and 
human urinary bladder and prostate tissues, the similarity of the $\alpha-1 \mathrm{~A}$ receptor expression in the bladder dome smooth muscle, and prostate smooth muscle (18). They found that the receptor expressions in the bladder dome and base, smooth muscle, connective tissue and urethelium differed in all three species. The same study failed to demonstrate the receptors in humans which were found at high levels in rat and monkey bladder dome urothelium. Moro et al., in the study where the receptor functions were examined in the pig urothelium/lamina propria with the consideration that pigs would be a good model for humans, demonstrated the expressions of $\alpha-1 \mathrm{~A}>\alpha-1 \mathrm{~B}>\alpha-1 \mathrm{D}$, the levels of $\alpha-1 \mathrm{~A}$ and $\alpha-1 \mathrm{D}$ being greater than $-1 \mathrm{~B}$, and that they had contractile capacity as in the detrusor. As the authors report, $\alpha-1 \mathrm{~B}$ receptors are expressed mainly in cardiovascular system and lungs. These receptors are the main reason for side effects of these drugs such as hypotension or ortopnea (24). The results of these two studies prove that alpha AR expression may differ in different tissues. In our study, $\alpha-1$ AR distribution was examined in rat and human renal pelvis and calyces, and found that receptor expressions were similar in both species. Thus, rats could be a suitable model for the receptor studies related to the urinary system.

It is crucial in the targeting treatment to have information about the receptor distributions in order to optimize the effectivity by applying the medication for the adequate receptor. Benign prostate hyperplasia treatment with medications targeting receptor blockage $(25,26)$ made its way in the clinical practice with the kidney expulsion targeting treatments $(12,27)$.

Silodosin, for example, had been used on rats with the code KMD-3213 before it has been used by humans (28). Also, there are newer publications using $\alpha$ receptor blockers using rat models. Villa et al. investigated the effect of prazosin, tamsulosin and silodosin on rat and human ureters and demonstrated that rats can be used as human models (29). There are many studies about bladder detrusor muscle and receptors. Yazaki et al. demonstrated the effect of receptors in improving the storage dysfunction in a rat model with bladder outlet obstruction (25). Similar to that study,
$\mathrm{Gu}$ et al. managed rats with urinary obstruction with receptor blockers (26). With all these studies present, we believe that by the demonstration of receptor subtypes and distribution similarities of rats and men, rats may be a good model for novel treatments targeting receptors on human kidney.

Peristalsis begins with the contractions of renal calyces and pelvis. This was clearly demonstrated previously (2). Alpha receptors were found to be mediating ureteral contractions in rat models (3). As this was demonstrated in rat models, human researchers used this as a model before human research. There are several $\alpha$ receptor treatment studies concerning ureters, and even kidney stones (4-6).

Until recently, there was no medical therapy option for renal stones. A few studies have been conducted to evaluate the use of $\alpha$ receptor blockers after kidney stones were managed by Extracorporeal Shock Wave Lithotripsy (SWL) $(5,11)$. These studies suggest the usage of $\alpha$ blocker treatment following SWL of kidney stones, both for improving the outcomes and relieving pain $(5,27)$. However, the use of these receptor blockers is not based on evidence. There is not a single study comparing $\alpha$ receptors in humans and animal models.

Medical expulsative therapy (MET) is a commonly used therapy for facilitation ureteral stone passage. Alpha blocker agents are used, for both pain relief and relaxing smooth muscles to facilitate stone passage. This treatment also relieves pain and discomfort caused by double $\mathrm{j}$ catheters. Several publications have been published on this matter $(30,31)$. With the findings of our study, investigators may focus on facilitating the passage of renal calyx or pelvic stones.

The low number of human and rat specimens and the nature of human kidney specimens (harvested from cancerous tissues) are main limitations of this study.

In our study, we demonstrated $\alpha$ receptors in both human and rat renal pelvis and calyces with similar concentrations. We revealed similar $\alpha$ receptor concentrations in both human and rat tissues and therefore rat models will be able to be used for $\alpha$ receptor studies concerning renal pelvis and calyces. With this fact in mind, human stud- 
ies concerning alpha-receptor blockage may take place with evidence.

\section{CONCLUSION}

With the demonstration of the $\alpha$ receptors in rat kidneys and calyces, many receptor-based studies concerning both humans and rats can take place. Novel medication targeting these subtypes -in this matter $\alpha 1 \mathrm{~A}$ and $\alpha 1 \mathrm{D}$ for renal pelvis and calyces- may be helpful for expulsive therapy and/ or pain relief. With the demonstration of similar receptor densities between human and rat tissues, rat model may be useful for $\alpha$-receptor trials for renal pelvis and calyces. We believe that new studies on the alpha receptors in renal pelvis and calyces would contribute to the field significantly.

\section{CONFLICT OF INTEREST}

None declared.

\section{REFERENCES}

1. Sigala S, Peroni A, Mirabella G, Fornari S, Palazzolo F, Pezzotti G, et al.: Alpha1 adrenoceptor subtypes in human urinary bladder: sex and regional comparison. Life Sci. 2004; 76: 417-27.

2. Iqbal J, Tonta MA, Mitsui R, Li Q, Kett M, Li J, et al.: Potassium and AN01/ TMEM16A chloride channel profiles distinguish atypical and typical smooth muscle cells from interstitial cells in the mouse renal pelvis. $\mathrm{Br} \mathrm{J}$ Pharmacol. 2012; 165: 2389-408.

3. Kobayashi S, Tomiyama Y, Maruyama K, Hoyano Y, Yamazaki Y, Kusama H: Effects of four different alpha(1)-adrenoceptor antagonists on alpha-adrenoceptor agonist-induced contractions in isolated mouse and hamster ureters. J Smooth Muscle Res. 2009; 45: 187-95.

4. Gurbuz MC, Polat H, Canat L, Kilic M, Caskurlu T: Efficacy of three different alpha 1-adrenergic blockers and hyoscine N-butylbromide for distal ureteral stones. Int Braz J Urol. 2011; 37: 195-200; discussion 201-2.

5. Zhu Y, Duijvesz D, Rovers MM, Lock TM: alpha-Blockers to assist stone clearance after extracorporeal shock wave lithotripsy: a meta-analysis. BJU Int. 2010; 106: 256-61.

6. Park HK, Choi EY, Jeong BC, Kim HH, Kim BK: Localizations and expressions of alpha-1A, alpha-1B and alpha-1D adrenoceptors in human ureter. Urol Res. 2007; 35: 325-9.
7. Hieble JP, Bylund DB, Clarke DE, Eikenburg DC, Langer SZ, Lefkowitz RJ, et al.: International Union of Pharmacology. X. Recommendation for nomenclature of alpha 1-adrenoceptors: consensus update. Pharmacol Rev. 1995; 47: 267-70.

8. Karabacak OR, Yilmazer D, Ozturk U, Sener NC, Saltas H, Karabacak $Y$, et al.: The presence and distribution of alpha adrenergic receptors in human renal pelvis and calyces. Urolithiasis. 2013; 41: 385-8.

9. Latifpour J, Morita T, O'Hollaren B, Kondo S, Weiss RM: Characterization of autonomic receptors in neonatal urinary tract smooth muscle. Dev Pharmacol Ther. 1989;13: 1-10.

10. Nickel JC: BPH: costs and treatment outcomes. Am J Manag Care. 2006; 12: S141-8.

11. Küpeli B, Irkilata L, Gürocak $S$, Tunç L, Kiraç $M$, Karaoglan $U$, et al.: Does tamsulosin enhance lower ureteral stone clearance with or without shock wave lithotripsy? Urology. 2004; 64: 1111-5.

12. Seitz C, Liatsikos E, Porpiglia F, Tiselius HG, Zwergel U: Medical therapy to facilitate the passage of stones: what is the evidence? Eur Urol. 2009; 56: 455-71.

13. Forray C, Noble SA: Subtype selective alpha1-adrenoceptor antagonists for the treatment of benign prostatic hyperplasia. Expert Opin Investig Drugs. 1999; 8: 2073-2094.

14. Weiss RM, Bassett AL, Hoffman BF: Adrenergic innervation of the ureter. Invest Urol. 1978; 16: 123-7.

15. Larsson B, Sjögren C, Andersson KE: Regional distribution of alpha-adrenoceptor subtypes in the female rabbit urethra. Acta Physiol Scand. 1986; 126: 39-43.

16. Andersson KE, Larsson B, Sjögren C: Characterization of the alpha-adrenoceptors in the female rabbit urethra. $\mathrm{Br} \mathrm{J}$ Pharmacol. 1984; 81: 293-300.

17. Itoh Y, Kojima Y, Yasui T, Tozawa K, Sasaki S, Kohri K: Examination of alpha 1 adrenoceptor subtypes in the human ureter. Int J Urol. 2007; 14: 749-53.

18. Walden PD, Durkin MM, Lepor H, Wetzel JM, Gluchowski C, Gustafson EL: Localization of mRNA and receptor binding sites for the alpha 1a-adrenoceptor subtype in the rat, monkey and human urinary bladder and prostate. J Urol. 1997; 157: 1032-8.

19. Hampel C, Dolber PC, Smith MP, Savic SL, Th roff JW, Thor $\mathrm{KB}$, et al.: Modulation of bladder alpha1-adrenergic receptor subtype expression by bladder outlet obstruction. J Urol. 2002; 167: 1513-21.

20. Lee G, Park H, Park HS, Lee JG: Modulation of alpha 1 adrenergic receptors on urinary bladder in rat spinal cord injury model. Int Neurourol J. 2012; 16: 62-8.

21. Michel MC, Vrydag W: Alpha1-, alpha2- and betaadrenoceptors in the urinary bladder, urethra and prostate. Br J Pharmacol. 2006; 147(Suppl 2): S88-119.

22. Goepel M, Wittmann A, Rübben H, Michel MC: Comparison of adrenoceptor subtype expression in porcine and human bladder and prostate. Urol Res. 1997; 25: 199-206. 
23. Noble AJ, Chess-Williams R, Couldwell C, Furukawa $\mathrm{K}$ Uchyiuma T, Korstanje C, et al.: The effects of tamsulosin, a high affinity antagonist at functional alpha $1 \mathrm{~A}$ - and alpha 1D-adrenoceptor subtypes. Br J Pharmacol. 1997; 120: 231-8.

24. Moro C, Tajouri L, Chess-Williams R: Adrenoceptor function and expression in bladder urothelium and lamina propria. Urology. 2013; 81: 211.e1-7.

25. Yazaki J, Aikawa K, Shishido K, Yanagida T, Nomiya M, Ishibashi K, et al.: Alpha1-adrenoceptor antagonists improve bladder storage function through reduction of afferent activity in rats with bladder outlet obstruction. Neurourol Urodyn. 2011; 30: 461-7.

26. Gu B, Reiter JP, Schwinn DA, Smith MP, Korstanje C, Thor $\mathrm{KB}$, et al.: Effects of alpha 1-adrenergic receptor subtype selective antagonists on lower urinary tract function in rats with bladder outlet obstruction. J Urol. 2004; 172: 758-62.

27. Gravas S, Tzortzis V, Karatzas A, Oeconomou A, Melekos MD: The use of tamsulozin as adjunctive treatment after ESWL in patients with distal ureteral stone: do we really need it? Results from a randomised study. Urol Res. 2007; 35: 231-5.

28. Akiyama K, Hora M, Tatemichi S, Masuda N, Nakamura S, Yamagishi $\mathrm{R}$, et al.: KMD-3213, a uroselective and longacting alpha(1a)-adrenoceptor antagonist, tested in a novel rat model. J Pharmacol Exp Ther. 1999; 291: 81-91.
29. Villa L, Buono R, Fossati N, Rigatti P, Montorsi F, Benigni $F$, et al.: Effects by silodosin on the partially obstructed rat ureter in vivo and on human and rat isolated ureters. $\mathrm{Br} \mathrm{J}$ Pharmacol. 2013; 169: 230-8.

30. Wang CJ, Huang SW, Chang CH: Effects of specific alpha1A/1D blocker on lower urinary tract symptoms due to double-J stent: a prospectively randomized study. Urol Res. 2009; 37: 147-52.

31. Lamb AD, Vowler SL, Johnston R, Dunn N, Wiseman OJ: Meta-analysis showing the beneficial effect of $\alpha$-blockers on ureteric stent discomfort. BJU Int. 2011; 108: 1894-902.

Correspondence address: Nevzat Can Sener, MD Ministry of Health, Ankara Diskapi Yildirim Beyazit Education and Research Hospital, Department of Urology, Ankara, Turkey Telephon: + 90312 596-2244 E-mail: cansener14@gmail.com 